6 Jochelson K, Mothibeli M, Leger J-P. Human immunodeficiency virus and migrant labor in South Africa. Int $\mathcal{F}$ Health Serv 1991;21:157-73.

7 Hunt CW. Migrant labor and sexually transmitted disease: AIDS in Africa. 7 Health Soc Behav 1989:30:353-73.

8 Baldo M, Cabral AJR. Low intensity wars and social determinations of the HIV transmissions: the search for a new paradigm to guide research and control of the HIV-AIDS pandemic. In: Stein Z, Zwi A, eds. Action on AIDS in southern Africa. Maputo conference on health in transition in southern Africa, April 1990. New York: Committee for Health in Southern Africa, 1991 34-43.

9 Piot P, Holmes KK. Sexually transmitted disease. In: Warren KS, Mahmoud AAF, eds. Tropical and geographical medicine. 2nd ed. New York: McGraw Hill, 1988:894-910.

10 Rosenfield PL. Social determinants of tropical disease. In: Warren KS, Mahmoud AAF, eds. Tropical and geographical medicine. 2nd ed. New York: McGraw Hill, 1988:197-205.

11 Freudenterg $N$. Health education for social change: a strategy for public health in the US. International fournal of Health Education 1981;24:1-8.
12 Bassett MT, Mhloyi M. Women and AIDS in Zimbabwe: the making of an epidemic. Int $\mathcal{A}$ Health Serv 1991;21:143-56.

13 Freudenberg N, Lee J, Silver D How black and Latino community organizations respond to the AIDS epidemic: a case study in one New York City neighbourhood. AIDS Education and Prevention 1989;1:12-2.

14 Green LW, Raeburn JM. Health promotion. What is it? What will it become Health Promotion 1988;3:151-9.

15 Ottawa charter for health promotion. Health Promotion 1986;1:3-5. Freudenberg N. AIDS prevention in the United States: lessons from the firs decade. Int f Health Serv 1990;20:589-99.

17 Packard RM, Epstein P. Epidemiologists, social scientists, and the structure of medical research on AIDS in Africa. Soc Sci Med 1991;33: $771-94$.

18 Sanders D, Abdulrahman S. AIDS in Africa: the implications of economic recession and structural adjustment. Health Policy and Planning 1991;6: $157-65$

19 Nabarro D, McConnell C. The impact of AIDS on socioeconomic development. AIDS 1989;3 (suppl 1):S265-72.

\title{
Needs assessment, priority setting, and contracts for health care: an economic view
}

\author{
Cam Donaldson, Gavin Mooney
}

The publication of the Acheson report led to the proposal that directors of public health should be responsible for assessing the needs of their local populations. ' This idea was then taken up in the white paper on the NHS, which reaffirmed their responsibility to assess the needs of the population but as a means of informing health boards/authorities as purchasers of care. ${ }^{2}$ One way of informing the contracting process, it is thought, is to assess the health care needs of the population, to determine what health care should be provided and to what extent.

We propose here a method for determining priorities in health care based not on total needs assessment but on economic evaluation. We believe this method is more relevant for health care contracting. Its widespread use will ensure that, no matter what total needs are, health care resources are used in such a way as to maximise the benefits from them.

We first introduce the economic approach to priority setting and outline its advantages over needs assessment. Finally, we discuss how health care professionals might in practice use the economic approach in setting priorities and contracts.

\section{Setting priorities: the economic approach}

Setting priorities starts from the fact that resources are scarce. Contracting is an arrangement between purchasers and providers about both what to provide and what not to provide. If the aim is to maximise health gains to the community within the resources available priority setting should become an integral part of contracting.

Tackling one particular health problem denies society the opportunity of using those resources to tackle other health problems. There are opportunities forgone and thereby opportunity costs. The aim of priority setting is to ensure that the health benefits resulting from health care are maximised and that the opportunity costs of health care are minimised. This can be done only by comparing health care interventions with each other in terms of health gains produced for resources spent.

The economic approach to priority setting addresses two related questions: Is a health care intervention worth while? Given that it is worth while, what is the best way of providing it?

Policy questions often relate to changing the scale of a health care intervention-providing more of it or less of it. Evaluation must then take account not of the total costs and benefits of the whole programme but of the incremental (or marginal) costs and benefits (that is, the difference between costs and benefits before and after the change in scale).

A comparison using a league table of QALYs (quality adjusted life years) of some marginal costs and benefits is presented in table I. ${ }^{4-6}$ Certainly, QALYs can be criticised as measures of health ${ }^{7-10}$ but they are among the best measures currently developed. Consequently, assuming that the objective of health care policy is to maximise the contribution of health care resources to the health (defined here as QALYs) of the community, then more resources within the health care budget should be allocated to treatments with a low marginal cost per QALY and less to those with a high marginal cost per QALY gained. Thus, assuming all health care treatments available are those listed in table I, other things being equal, dialysis should be contracted and chiropody expanded; more QALYs would be produced without any increase in expenditure.

TABLE I-Illustrative marginal cost per QALY league table

\begin{tabular}{lc}
\hline Treatment & $\begin{array}{c}\text { Marginal cost per } \\
\text { QALY gained } \\
\text { (1988 prices) } \\
\text { Special chiropody at home (>75 years) }\end{array}$ \\
\hline GP's advice to give up smoking & 199 \\
Chiropody in a clinic (ages 60-75) & 238 \\
Pacemaker implantation & 603 \\
Hip replacement & 832 \\
Valve replacement for aortic stenosis & 891 \\
Coronary artery bypass grafting: & 1096 \\
Severe angina, left main disease & 1231 \\
Severe angina, triple disease & 1505 \\
Moderate angina, left main disease & 1584 \\
Kidney transplantation & 6072 \\
Haemodialysis at home & 13069 \\
Haemodialysis in hospital & 16634 \\
\hline
\end{tabular}

Sources: Williams, ${ }^{+5}$ Bryan et al.

Setting priorities: the needs assessment approach

The traditional epidemiological approach to needs assessment would appear to be to measure the total amount of ill health in the community, categorised by disease, and then use this information to set priorities for allocating resources between different diseases. "Need" could be measured by lives lost, life years lost, morbidity, or loss of social functioning.

Using some broad definition of need epidemiologists would then set priorities using data of the sort presented in table II. The first priority in health care resource allocation, and in purchasing care, would go to ischaemic heart disease.

Nevertheless, it is not clear from such data how 
many resources ischaemic heart disease would receive relative to other diseases. Should all heart disease be treated before the others receive funding? Would heart disease receive funding until it came down to the level of life years lost from cerebrovascular disease? Would the health care budget be divided pro rata with the numbers of life years lost from each disease?

TABLE II - Estimated years of potential life lost before age 85, England and Wales 1984: top 10 causes

\begin{tabular}{lc}
\hline & Thousands \\
\hline Ischaemic heart disease & 1869 \\
Cerebrovascular disease & 574 \\
Cancer of trachea, bronchus, and lung & 549 \\
Cancer of colon & 548 \\
Cancer of genitourinary organs & 302 \\
Other heart disease and hypertension & 258 \\
Cancer of breast & 239 \\
Congenital anomalies & 201 \\
Other respiratory diseases & 171 \\
Motor vehicle traffic accidents & 170 \\
\hline Source: OPCS." &
\end{tabular}

The priorities established by using such a form of needs assessment are likely to be different from those established through economic evaluations. Priority setting using this method will tend to favour treating the big killers. This may conflict with the results of economic evaluations. For instance, foot problems are unlikely to rank highly in society's list of health care needs, yet chiropody represents good value for money in terms of health gains relative to extra resources spent.

Such a conflict arises because there are two major flaws in the needs assessment approach to priority setting. Firstly, "need" is a red herring. It is changes in need met (or marginal met need) that should be the outcome factor. Secondly, changes in costs resulting from interventions are ignored.

\section{A practical approach to contracting and priority setting}

We assume that in choosing between bids for a particular contract the choice will be based on what is most cost effective. This paper deals only with priority setting at the level of allocative efficiency-that is, since not everything that is desirable for the health of the local population can be done, what is to be done, to what extent, and what is to be left undone or at best delayed?

There are four key principles underlying the proposed approach: $(a)$ resources are scarce, $(b)$ ineffective treatments must be discarded, $(c)$ even if treatments are effective, they should be pursued only to the extent that costs remain less than benefits, $(d)$ the focus is on changes in service delivery - and the costs and benefits of those changes.

In an ideal world what would follow would be a costbenefit assessment of all treatments at all possible levels of provision and the selection of those that yielded the greatest benefit per pound spent. A more pragmatic strategy is as follows.

Firstly, an authority must decide what "programmes" are considered to be relevant in the light of the authority's strategy in terms of disease groups, client groups, or specialties. Each programme should meet the following requirements. (1) It should contain some set of activities for which there is some homogeneity in the outputs. (2) It should be meaningful in terms of the authority's strategy to talk about priorities within programmes. (3) The cost of activities contained in each programme must be known, at least roughly.

Secondly, each programme should then be examined to see whether some reallocations within the programme can produce an overall increase in benefits. The way of doing this is as follows: (a) decide which treatments are so valuable or simply have to be provided that it would be a waste of time analysing them; $(b)$ of the remainder, start by assessing which areas are most open to change; $(c)$ for each existing programme in turn, divide it into subprogrammes and then ask what the effect would be (if possible in terms of both workload and health) of reducing spending by $£ 100000$ and of increasing it by $£ 100000$. Judgments could then be made on whether some subprogrammes could be cut to allow other subprogrammes to get extra funding so that there would be more benefits in total. In other words the losing subprogramme would be judged to lose less benefit than the gaining subprogramme gained. Such a process should be continued until within the overall resources there is no possibility of getting a greater benefit overall.

Thirdly, the final process in this strategy would be to go through the same procedure for the programmes as a whole.

\section{Conclusion}

Two considerations arise from our proposed approach. Firstly, it does not require any assessment of total needs. Secondly, the key concept is that of benefit and of getting the greatest benefit for each pound spent. Following this approach will ensure that met need (or health outcome) is maximised with the health care resources at society's disposal while avoiding the need to measure need.

1 Secretary of State for Social Services. Public health in England: the report of the committee of inquiry into the future development of the public health function. committee of inquiry into

2 Secretaries of State for Health, Wales, Northern Ireland and Scotland. Working for patients: the health service: caring for the 1990s. London: HMSO, 1989.

3 Grampian Health Board. Working for health: towards a local health strategy for Grampian. Aberdeen: Grampian Health Board, 1991.

4 Williams A. Economics of coronary artery bypass grafting. BMF 1985;291 326-9.

5 Williams A. Health economics: the cheerful face of the dismal science? In Williams A, ed. Health and economics. London: Macmillan, 1987:1-11.

6 Bryan S, Parkin D, Donaldson C. Chiropody and the QALY: a case study in assigning categories of disability and distress to patients. Health Policy 1991;18:169-85.

7 Harris J. QALYfying the value of life. Fournal of Medical Ethics 1987;13: $117-23$.

8 Donaldson C, Atkinson A, Bond J, Wright K. Should QALYs be programmespecific? Foumal of Health Economics 1988;7:239-57.

9 Loomes G, McKenzie L. The use of QALYs in health care decision making. Social Science and Medicine 1989;28:299-308.

10 Mooney G, Olsen JA. QALYs: where next? In: McGuire A, Fenn P, Mayhew $\mathrm{K}$, eds. Providing health care: the economics of altermative systems of finance and delivery. Oxford: Oxford University Press, 1991.

11 Office of Population Censuses and Surveys. Mortality statistics 1984. London: HMSO, 1986. (OPCS Series DH1, No 16.)

(Accepted 14 August 1991) 